\title{
Cyber-Physical Systems for Real-time Management in the Urban Water Cycle*
}

\author{
$1^{\text {st }}$ Congcong Sun \\ Institut de Robòtica I Informàtica \\ Industrial (CSIC-UPC) \\ Barcelona, Spain \\ csun@iri.upc.edu
}

\author{
$2^{\text {nd }}$ Gabriela Cembrano \\ Institut de Robòtica I Informàtica \\ Industrial (CSIC-UPC) \\ Water Technology Centre \\ (CETaqua) \\ Barcelona, Spain
}

\author{
$3^{\text {rd }}$ Vicenç Puig \\ Institut de Robòtica I Informàtica \\ Industrial (CSIC-UPC) \\ Barcelona, Spain
}

\author{
$4^{\text {th }}$ Jordi Meseguer \\ Water Technology Centre \\ (CETaqua) \\ Barcelona, Spain
}

\begin{abstract}
In the last few decades, water systems management has been increasingly developed into cyber-physical systems. They are based on advanced intelligent systems embedded with controllers, sensors and actuators to enable efficient use of water, energy consumption, emergency response and environmental guarantee. This paper provides an overview about cyber-physical system in reliable and efficient management of urban water cycle. A real pilot based on the Badalona urban drainage water network is provided as a case study.
\end{abstract}

Keywords-efficient; reliable; cyber-physical system; urban water cycle; water management.

\section{Introduction}

Water is a critical element for life and development. Due to increased water usage, in addition to the growing negative impacts of climate change, water scarcity is an increasing concern, which motivates the development of reliable and efficient management of water systems.

The urban water cycle (UWC) includes several systems, namely: natural water sources management, drinking water treatment plants for achieving required water quality; drinking water transport and distribution systems to deliver water from treatment plants to users, sewer systems which carry waste- and rainwater together and wastewater treatment plant (WWTP), which treats used water before releasing it to the environment. All these systems are tightly interconnected and managed by computing and control systems, as in Fig. 1

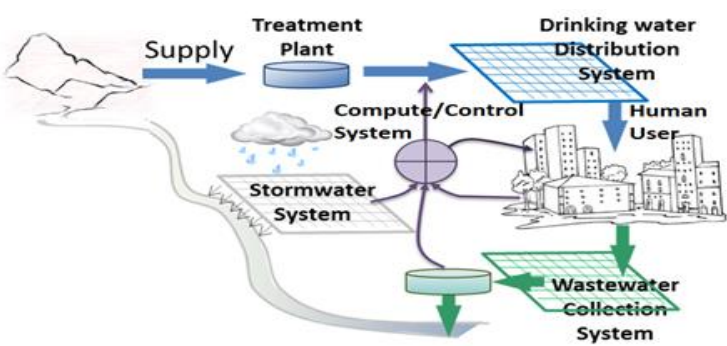

Fig. 1. Control system of the whole urban water cycle

Cyber-physical systems (CPSs) are networked intelligent systems embedded with sensors, controllers and actuators which are designed to interact with the physical world and human users with the aim of supporting real-time management and guaranteed performance in safety critical applications [1]. These features of CPS also include the partial autonomy of subsystems, the possibility of emerging behaviors, and a continuous evolution over the whole life-cycle of the systems.

Due to interactions and networked control of the physical world, the UWC can be viewed as a cyber physical system of systems (CPSoS). A representation of the CPSoS of the complete water cycle is shown in Fig. 2, where water hydraulic and quality conditions are monitored in real-time. Hydrodynamic modelling is integrated with real-time measurements to generate quality and hydraulic models for optimal control and diagnosis. Drinking water system (DWS) and urban drainage system (UDS), which are the main parts in the water cycle, may be considered as two different CPSs.

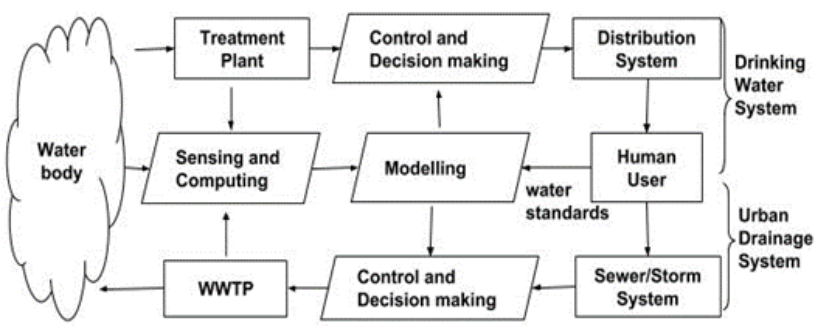

Fig. 2. Cyber-physical system of urban water cycle

The objective of this paper is to provide an overview about reliable and efficient management of systems in UWC under the paradigm of CPS. Section of Introduction introduces the CPS and how systems in UWC can be considered as CPS. Distributed and integrated management architectures for DWS and UDS are presented in Section I. Section II presents the modelling and control methods. Then, a real pilot, based on Badalona urban drainage system has been used as case study in Section III. The discussion and conclusions are provided in the Section IV.

\section{MANAGEMENT ARCHITECTURE}

In practice, systems in water cycle are still operated separately, but recent developments have shown the benefits of 
coordinated management in several parts of the cycle [9][10]. In this work, two main systems are considered: DWS and UDS.

\section{A. Drinking Water Systems}

In DWS, real-time network monitoring, control and consumer demand are still routinely operated separately, without taking full advantage of the existing data in different information systems. Therefore, it is really important to develop integrated management systems

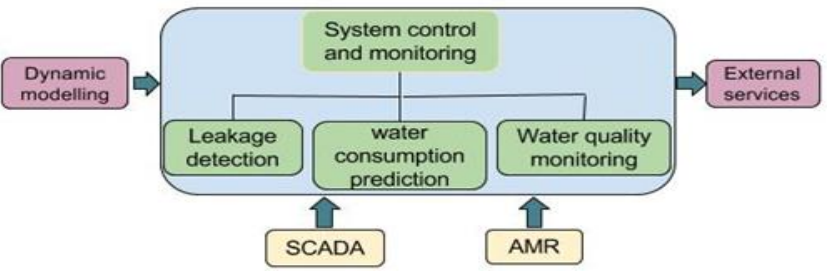

Fig. 3. Integrated structure for Drinking water system

As shown in Fig. 3, an integrated structure for DWS is a decision support system which handles real-time interactions between SCADA (supervisory control and data acquisition), telemetry, and AMR (automatic metering reading), with realtime databases and the specific water management modules for operational control, monitoring and demand management, with appropriate graphical user interface layers and connections to geographical information systems (GIS). The functions of the integrated solution to DWS are: (1) AMR provides utilities with data from demand; (2) SCADA provides flow, pressure and level values from elements of the whole system; (3) Network will obtain inputs from different sources, including GIS tools; (4) Real-time network monitoring alerts the operator about unusual patterns in the minimum night flows for a specific district metered area from the SCADA system; (5) Real-time validation of sensor data and actuator status; (6) Real-time control for optimizing the whole system.

\section{B. Urban Drainage Systems}

The sewer network, WWTP and receiving environment may be considered as one integrated system, called integrated UDS. The sewer network collects and carries the mixed sewage of rain water and urban wastewater to the WWTP for treatment before it is released to the environment. During rain events, the UDS may be overloaded and produce combined sewer overflows (CSO), which are harmful to the environment [2][3].

Recently, the sewer network and WWTP are mainly operated separately [2]. In order to optimize UDS efficiently, integrated CPS paradigm for the UDS, which coordinate the sewer network and WWTP for better performance is proposed.

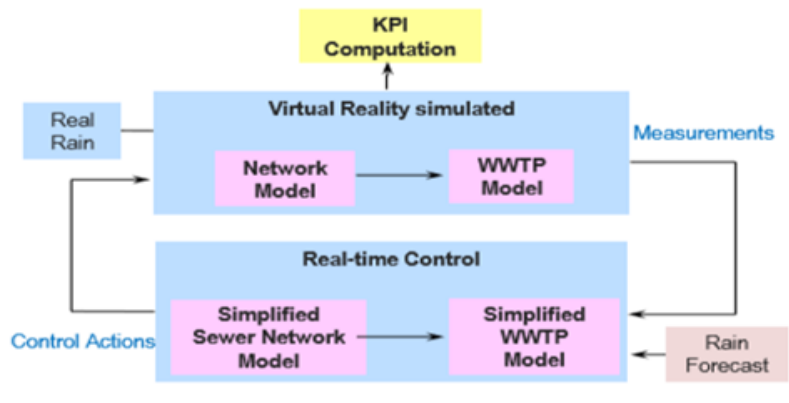

Identify applicable funding agency here. If none, delete this text box.
Fig. 4. Integrate structure for Urban Drainage System

As shown in Fig. 4, the integrated closed-loop simulation and optimization paradigm for UDS has been proposed. The sewer network and WWTP have been optimized with real-time control, using simplified models for both sewer network and WWTP. Modelling and control methods

There are plenty of nonlinear models useful for off-line operation for the UWC. However, for on-line operating purposes of large water networks, conceptual control-oriented modelling methods which can represent the main network dynamic with simplicity and flexibility should be used.

\section{MODELLING AND CONTROL METHODS}

\section{A. Urban Drainage Systems}

In [6], hydraulic models of detention tank in UDS have been applied. In [7], simplified quality models for total suspended solid (TSS) in the sewers, junction nodes are presented.

Considering the hydraulic model of tank [6] and the TSS models in sewers $\left(T S S_{\text {in }}\right.$ and $\left.T S S_{\text {out }}\right)$ [7], the dynamic of TSS in detention tank $\mathrm{M}$ is:

$$
\begin{aligned}
& \quad M(t+1)=(1-a) M(t)+\Delta t\left(Q_{\text {in }}(t) T S S_{\text {in }}(t)-\right. \\
& \left.Q_{\text {out }}(t) T S S_{\text {out }}(t)\right)
\end{aligned}
$$

where $a$ is a parameter talking values between -1 and 1 to represent sedimentation/erosion effects. In this paper, $a$ is set as 0.3 to show the first results of the experiment.

\section{B. Model Predictive Control}

Model predictive control (MPC), which can optimize control with the current measurements and also predictive behaviors in a certain horizon, has been implemented as an efficient method to produce optimal strategies for both DWS and also UDS.

Considering for illustrative purposes, the case of UDS, the MPC controller which considers evolution of flows and TSS can be represented in the state space as follows:

$$
\min _{x, u} J(x, u, w)
$$

s.t.

$$
x(t+1)=f(x(t), u(t), w(t))
$$

where $\boldsymbol{x}$ is system state for water volume and suspended solids in tank; $u$ is control variable of flow in commanded gate; $\boldsymbol{w}$ is disturbance vector related to rain intensity and runoff.

Five performance indexes for MPC are considered: minimize CSO; minimize suspended solids discharges; maximize usage of WWTP; minimize flooding in critical points and smooth actions of control variables. The objective priorities are established by weights defined by system manager [8]:

$$
\begin{aligned}
& J(x, u, w)=a_{c s o} J_{\text {cso }}+a_{w w t p} J_{w w t p}+a_{\text {safe }} J_{\text {safe }}+ \\
& a_{\text {smooth }} J_{\text {smooth }}+a_{\text {Mass }} J_{\text {Mass }}
\end{aligned}
$$

\section{CASE Study BASEd BADAlona PILOT}

Badalona is one of the pilot sites considered in project LIFEEFFIDRAIN. It is part of the Barcelona metropolitan area, with 
more than 215.654 inhabitants in land area of $21.2 \mathrm{~km}^{2}$, which occasionally suffers heavy rainfalls of great intensity and flash flood events. Fig. 5 is a simplified representation of the Badalona UDS which contains one detention tank with contributions from two different catchments, where catchments VT1 and VT3 send water through G1 and G2 to the detention tank T1. Pump P draws water through T1 to the WWTP before releasing it to the sea. When the wastewater capacity of WWTP is exceeded, CSO occurs.

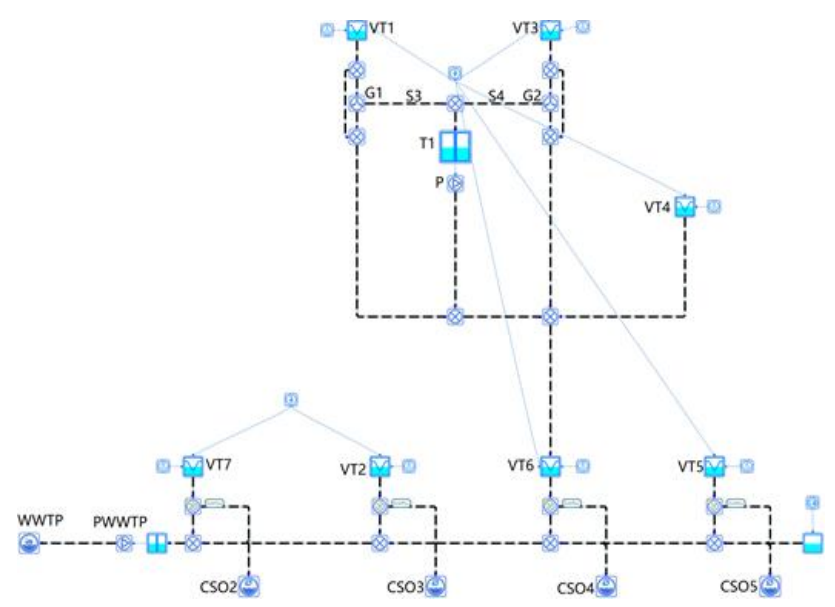

Fig. 5. Badalona Urban Drainage System

\section{A. Definition of Scenarios}

For the purpose of validating the MPC strategies considering quantity and quality, an artificial scenario is created, where catchment VT1 has a significantly higher TSS than catchment VT3. It is important to remark that these TSS concentrations do not correspond to real historic data, but they are created to test the ability of the optimizer to deal with the decisions on detention with waters of different qualities.

Additionally, the WWTP capacity is considered as time varying. Clearly, knowledge of the real plant capacity when optimizing the sewer network operation improves the ability to prevent CSO. However, sewer network operation usually does not have this information and computes its strategies considering a nominal value for the plant capacity.

MPC has been chosen as the controller and optimized using GAMS optimization library [4]. Two scenarios are included:

Scenario 1: Optimizing the sewer network operation with integrated CPS structure which considers the time varying WWTP capacity, comparing with results of optimizing sewer network and separately with a constant nominal WWTP capacity;

Scenario 2: Comparing optimal results of UDS using the quantity-and-quality objectives with the optimal results with only quantity objective.

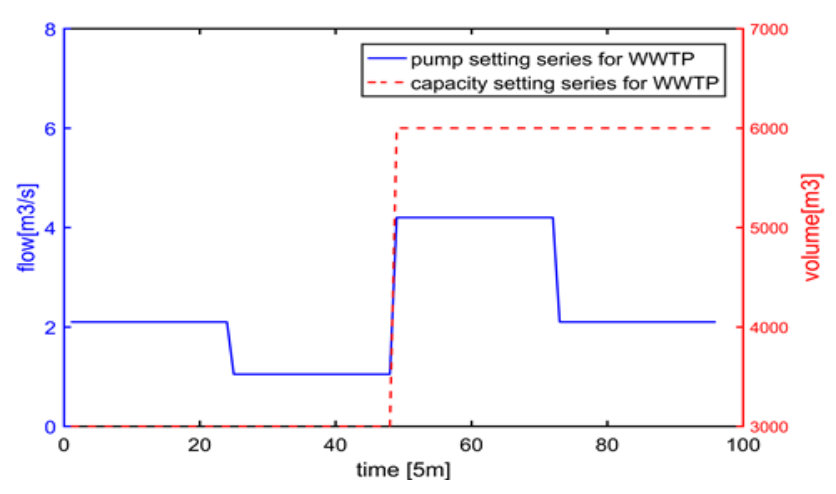

Fig. 6. WWTP time-varying capacity

\section{B. Results Validation}

Fig. 7 presents the CSO produced by integrated CPS structure has been reduced $36 \%$ comparing with CSO produced by optimizing sewer network separately, which only considers WWTP capacity as constant value. In the CPS structure of UDS, WWTP has been integrated considered in the optimization process, the modified capacity is known by the MPC controller to adjust the working strategy of detention tank and other elements in UDS to produce minimal CSO. Otherwise, in the separate control structure, the sewer network continues sending the same amount of wastewater to WWTP when the capacity has been enlarged or reduced, which does not take full advantage of the WWTP capacity has been used and more CSO released.

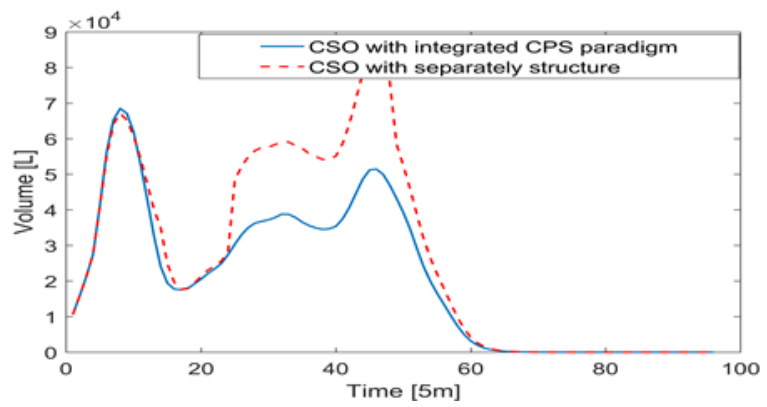

Fig. 7. CSO comparisons of scenario 1

Scenario 2 compares control strategies obtained with quantity-and-quality objective, to those obtained using quantityonly objective. Obviously, when the controller does not consider quality, the control strategy will allow the filling of the tank from catchment VT1 and VT3 indifferently. However, when considering the water quality, the optimizer should produce a strategy that favors the detention of the most polluted water until it can be sent to the WWTP without CSO.

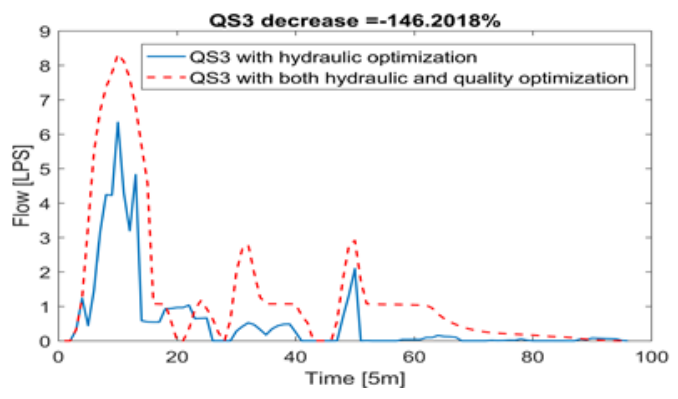




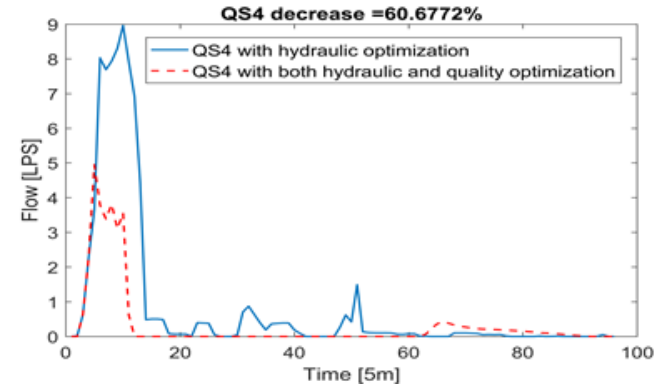

Fig. 8. Gate flows comparison between two different MPC controllers

Fig. 8 shows comparisons of flow for water inlet to the tank coming from VT1 and VT3. When applying quality optimization, flow from VT3 (QS4) has higher priority to be sent to tank T1 for detention than flow from VT1 (QS3), which has better quality and will be released firstly when CSO is unavoidable. As in Fig. 8, QS3 has been doubled, while QS4 has been decreased about $60 \%$ comparing flow from quantity objective.

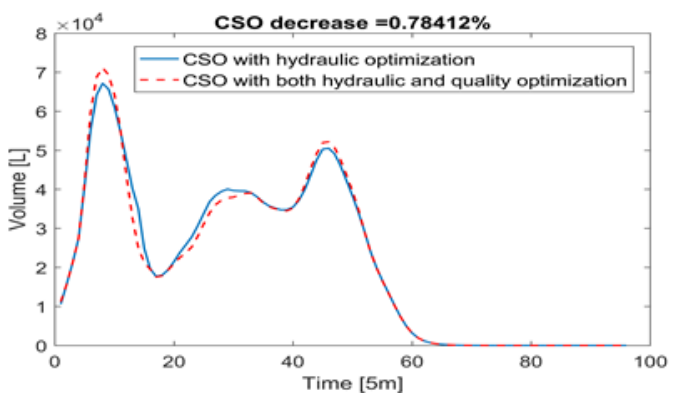

Fig. 9. CSO comparisons between two MPC controllers

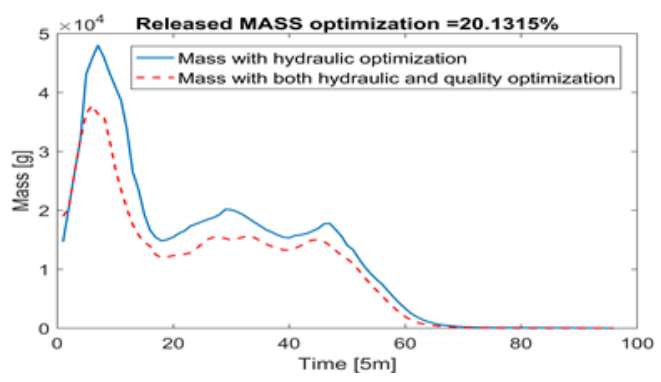

Fig. 10. Mass comparisons between two MPC controllers

Fig. 9 and Fig. 10 present CSO and released suspended solids comparisons between the two different MPC strategies, which proves that, released suspended solids has been decreased more than $20 \%$ by MPC with both hydraulic and quality optimizations than MPC with only hydraulic optimization, while with similar CSO flows.

\section{CONCLUSIONS}

This paper discussed management of the UWC under the CPS paradigm, including DWS and the UDS. Integrated CPS structure has been suggested for the UWC. Moreover, MPC and conceptual modelling approach have been presented. In the integrated CPS paradigm of UDS, treatment capacity modification of WWTP can be known by the controller to adjust working strategy of detention tank and other elements in UDS to reduce CSO. The quality objective of UDS can help to reduce the total impact of suspended solids in CSOs. The pilot based on the Badalona UDS has been applied as case study, which confirms that, with the integrated CPS management structure, UDS has been efficiently operated CSO has been reduced significantly. Besides, the quantity-and-quality control strategies can reduce released pollutant than quantity control.

\section{ACKNOWLEDGMENT}

This work is partially funded by grant LIFE EFFIDRAIN LIFE14 ENV/ES/00080 and supported by Spanish State Research Agency through María de Maeztu Seal of Excellence to IRI (MDM-2016-0656). The support of Bordeaux Metropole and the Badalona City Council (Ajuntament de Badalona) for the case study is also gratefully acknowledged.

\section{REFERENCES}

[1] W. Zhaohui, S. Houbing, W.W. David, G.O. Keat, X. Pengfei., Y. Qing, and S. Xianming. "Cyber-physical systems for water sustainability:Challenges and opportunities," IEEE Communications Magazine, 53(5), pp. 216-222, 2015.

[2] Becouze C., Bertrand-Krajewski J. -L., Demb' el'e A., Cren-Oliv'e C. and Coquery M. (2009). Preliminary assessment of fluxes of priority pollutants in stormwater discharges in two urban catchments in Lyon. Proceed. of the 13th IWA intern. confer. on Diffuse Pollu. and Integ. Waters. Manage., Seoul, South Korea.

[3] Joseph B., Ocampo-Mart'inez C. and Cembrano G. (2014). Hybrid modelling and receding horizon control of sewer networks. Water Resources Research, 50(11), 8497-8514.

[4] Wiuff R. (1985). Transport of suspended material in open and submerged streams, J. Environ. Eng. ASCE., 111(5), 774-792.

[5] Maruéjouls T., Vanrolleghem P. A., Pelletier G. and Lessard P. (2012) A phenomenological retention tank model using settling velocity distributions. J. Wat. Res., 46, 6857-6867.

[6] Cembrano G., Quevedo J., Salamero M., Puig V., Figueras J. \& Martí J. 2004: Optimal control of urban drainage systems. A case study. J. Contr. Engin. Pract., 12(1), 1-9.

[7] C.C. Sun, B. Joseph-Duran, T. Maruejouls, G. Cembrano, J. Meseguer, V. Puig and X. Litrico. Real-time control-oriented quality modelling in combined urban drainage networks. IFAC 2017 World Congress, Toulouse, France, 9-14 July, 2017, 4002-4007.

[8] V. Puig, G. Cembrano, J. Romera, J. Quevedo, B. Aznar, G. Ramón, J. Cabot. Predictive optimal control of sewer networks using CORAL tool: application to Riera Blanca Catchment in Barcelona. Water Science \& Technology, 2009, 60(4): 869-878.

[9] C.C. Sun, V. Puig and G. Cembrano. Temporal multi-level coordination techniques oriented to regional water network: Application to the Catalunya case study. Journal of Hydroinformatics, 16(4): 952-970, 2014

[10] D. Butler and M. Schütze. Integrating simulation models with a view to optimal control of urban wastewater systems. J. Environ. Modell. and Softw., 20(4):415-426.

[11] S. Kartakis, A. Fu, M. Mazo and J.A. McCann. Communication Schemes for Centralized and Decentralized Event-Triggered Control Systems. IEEE Transections on Control Systems Technology. PP(99), 1-14, 2017.

[12] R. Wright, E. Abraham, P. Parpas and I. Stoianov. Control of water distribution networks with dynamic DMA topology using strictly feasible sequential convex programming. Water Resources Research, 51(12), 9925-9941. 